\title{
Hands-on experiences for remotely taught analytical chemistry laboratories
}

\author{
Joel F. Destino ${ }^{1} \cdot$ Erin M. Gross ${ }^{1} \cdot$ Emily D. Niemeyer $^{2} \cdot$ Steven C. Petrovic ${ }^{3}$ \\ Published online: 9 January 2021 \\ (C) Springer-Verlag GmbH Germany, part of Springer Nature 2021
}

\section{Introduction}

When higher education transitioned to remote instruction in the spring of 2020 because of the COVID-19 pandemic, one of the most challenging aspects for many instructors of analytical chemistry courses involved how to engage students in hands-on laboratory experiences. The laboratory is where students gain practical experiences using techniques and instruments that are central to analytical chemistry. Many instructors also incorporate projects into the analytical chemistry laboratory where students have more autonomy in the design and execution of experiments. In project-based experiences, students need to propose hypotheses, design and execute experiments, and then interpret data to see whether conclusions can be drawn or experiments need to be redesigned and repeated.

With the realization that many courses would continue to be taught remotely in the fall of 2020 , hands-on laboratory

This contribution is part of a series featuring teaching analytical science during the pandemic in order to support instructors in preparing their courses.

Emily D. Niemeyer

niemeyee@southwestern.edu

Joel F. Destino

JoelDestino@creighton.edu

Erin M. Gross

ErinGross@creighton.edu

Steven C. Petrovic

petrovis@sou.edu

1 Department of Chemistry, Creighton University, Omaha, NE 68178, USA

2 Department of Chemistry and Biochemistry, Southwestern University, Georgetown, TX 78626, USA

3 Department of Chemistry, Southern Oregon University, Ashland, OR 97520, USA experiments were designed that students could complete while studying off campus. One approach described herein involves a series of experiments using carbonate species that incorporate gravimetry and titrimetry, which are topics typically included in an introductory quantitative analysis course. Another approach involves two experiments suitable for an instrumental analysis course. These involve an amperometric measurement for the analysis of glucose and fluorescence measurement for the analysis of riboflavin. The final approach involves a scaffolded experience where students build, study, and experiment with a cell phone spectrophotometer that they then use in an independent, self-designed project.

All of the experiments are inexpensive and safe for students to complete in a remote setting. Combined, these three different experiences provide a range of ways for instructors to incorporate hands-on experiments for students into online and hybrid analytical chemistry laboratory courses.

\section{Remote laboratory experiences based on carbonate chemistry}

A series of six at-home laboratory experiments were developed for quantitative analysis students at Southern Oregon University (SOU). These experiments involve the chemical analysis and reactivity of sodium carbonate and sodium bicarbonate (the materials in the Supplementary Information (ESM) have the handouts provided to students for each experiment). Experiments based on carbonate chemistry have several advantages: volatilization gravimetry (i.e., relating loss of $\mathrm{CO}_{2}$ to reaction stoichiometry) can easily be conducted at room temperature using an inexpensive digital scale; carbonate salts are incorporated into a wide range of consumer products and over-the-counter medicines; relatively pure carbonate salts are available from local supermarkets; carbonate acidbase chemistry is routinely covered in quantitative analysis 
courses; and the toxicity of sodium carbonate and sodium bicarbonate is low.

Approximately 6 weeks before the start of the fall term, students were contacted to inform them that remote laboratory instruction would be based on the at-home laboratory experiments shown in Table 1. Students were also provided with a shopping list of instrumentation, materials, and reagents shown in Table 2. Since assembling the at-home laboratory kit by the end of the first week of the term is work that students would not perform with face-to-face instruction, $10 \%$ of each student's lab grade was based on emailing a photo of their athome laboratory kit containing all of the items listed in Table 2. The cost of the instrumentation, which was priced through an online vendor, was approximately $\$ 60$. The cost of all the reagents and samples priced through a big box store was approximately $\$ 40$. Since many of the reagents and kitchen supplies (e.g., lidded jars, measuring cups, and measuring spoons) are commonly found in households, the full cost of the kit was expected to be less than $\$ 100$ for many students. In order to mitigate the expense of the kit and to acknowledge the remote nature of the quantitative analysis lab, students were not charged the usual $\$ 30$ lab fee associated with the course. Attributes of these at-home experiments include using glassware and balances, working with real samples, preparing solutions, pipetting, and titrations.

It was particularly important to develop experiments for remote learning that were inexpensive, flexible, and accessible to a range of student circumstances. At-home experiments using carbonate chemistry as the theme fulfilled these requirements. None of the experiments requires a heat source (e.g., a flame, hotplate, or oven). Only a surface and sink with running water are needed, which allowed students to complete these experiments at home or in campus residences. Each experiment was introduced during lab recitation, which was conducted synchronously via Zoom. Students could access their instructor remotely via Zoom during the normally scheduled 3-h lab period, as well as office hours, to address experimental difficulties. Students were allowed to conduct these experiments asynchronously as their schedule permitted. At SOU, students purchase their own protective equipment, including safety goggles, a lab coat, and appropriate dress to wear while performing experiments and this includes at-home experiments. Two of the six experiments were written up as lab reports, and students were provided with a rubric and an exemplar of a well-written report. Students wrote down the purpose, procedure, data, calculations, and results for each of the remaining experiments and emailed copies of their notebook pages to the instructor for grading. On the whole, interactions with students were less numerous and spontaneous than with face-to-face instruction. In some cases, this led to greater turnaround times when providing feedback on experimental difficulties. However, requiring students to complete pre-lab exercises allowed the instructor to assess student's prior knowledge and address potential misunderstandings. In addition,

Table 1 At-home quantitative analysis experiments and associated analysis and measurement skills addressed in each experiment

\begin{tabular}{|c|c|c|}
\hline Experiment title & $\begin{array}{l}\text { Analytical equipment } \\
\text { required }\end{array}$ & Skills addressed \\
\hline Volumetric Pipet Calibration & $\begin{array}{l}\text { 25-mL volumetric pipet } \\
\text { digital scale }\end{array}$ & $\begin{array}{l}\text { Working with volumetric glassware and a digital scale } \\
\text { Pipetting liquids } \\
\text { Significance tests on real data ( } t \text { test for one experimental mean, } F \\
\quad \text { test, } t \text { test for two experimental means) }\end{array}$ \\
\hline $\begin{array}{l}\text { Determination of carbonate/bicarbonate salts in } \\
\text { over-the-counter antacid preparations }\end{array}$ & Digital scale & $\begin{array}{l}\text { Working with a digital scale } \\
\text { Working with antacid as a "standard" (known mass of } \mathrm{NaHCO}_{3} \text { or } \\
\mathrm{CaCO}_{3} \text { ) } \\
\text { Significance tests on real data ( } t \text { test for one experimental mean) }\end{array}$ \\
\hline $\begin{array}{l}\text { Determination of carbonate/bicarbonate salts in a } \\
\text { consumer product }\end{array}$ & Digital scale & $\begin{array}{l}\text { Development of analytical methods } \\
\text { Preparing reagents } \\
\text { Working with real samples }\end{array}$ \\
\hline Assay of washing soda as a secondary standard & Digital scale & $\begin{array}{l}\text { Determining purity (assay) } \\
\text { Working with a secondary standard }\end{array}$ \\
\hline $\begin{array}{l}\text { Determination of ascorbic acid in a vitamin } \mathrm{C} \text { tablet } \\
\text { by potentiometric titration }\end{array}$ & $\begin{array}{l}25-\mathrm{mL} \text { volumetric pipet } \\
100 \text {-mL volumetric flask } \\
\mathrm{pH} \text { wand } \\
\text { Digital scale }\end{array}$ & $\begin{array}{l}\text { Performing titrations } \\
\text { Generating titration curves } \\
\text { Numerical differentiation } \\
\text { Graphical analysis (determining } \mathrm{pK}_{\mathrm{a}} \text { of ascorbic acid) } \\
\text { Preparing reagents }\end{array}$ \\
\hline $\begin{array}{l}\text { Solubility of potassium bitartrate (Cream of Tartar) by } \\
\text { acid-base titration }\end{array}$ & $\begin{array}{l}25-\mathrm{mL} \text { volumetric pipet } \\
100-\mathrm{mL} \text { volumetric flask } \\
\text { Digital scale }\end{array}$ & $\begin{array}{l}\text { Working with volumetric glassware and a digital scale } \\
\text { Pipetting solutions } \\
\text { Performing titrations } \\
\text { Preparing reagents } \\
\text { Significance tests on real data ( } t \text { test for one experimental mean) }\end{array}$ \\
\hline
\end{tabular}


Table 2 List of equipment, reagents, and samples for the at-home quantitative analysis labs

\begin{tabular}{|c|c|c|}
\hline Instrumentation & Reagents/materials & Samples \\
\hline $\begin{array}{l}\text { Accuweight Digital Pocket Scale (model IC255, } \\
300 \text { g capacity, } 0.01 \mathrm{~g} \text { resolution) }\end{array}$ & Distilled water (store brand, 1 gal) & $\begin{array}{l}\text { Alka-Seltzer (original } 36 \text { count) or Tums ( } 500 \\
\text { or } 1000 \mathrm{mg} \mathrm{CaCO}, 72 \text { count) }\end{array}$ \\
\hline $\begin{array}{l}\text { Digital handheld } \mathrm{pH} \text { meter, 3-point calibration with } \\
\text { buffer packets }\end{array}$ & Vinegar (store brand, 1 quart) & $\begin{array}{l}\text { Carbonate/bicarbonate-based consumer product } \\
\text { of student's choosing }\end{array}$ \\
\hline Volumetric pipet ( $25 \mathrm{~mL}$, class A) & Citric acid (ball, 7.5 oz.) & Vitamin C tablets (500- or 1000-mg dose) \\
\hline $\begin{array}{l}\text { Heathrow Scientific Large Rubber Pipet Bulb } \\
\text { (HD20630B) }\end{array}$ & Washing soda (Arm and Hammer, 55 oz.) & \\
\hline Volumetric flask (100 mL, polypropylene, class B) & Isopropyl alcohol (store brand, $32 \mathrm{oz}$.) & \\
\hline Plastic syringe ( 20 or $35 \mathrm{~mL}$ capacity) & Cream of Tartar (store brand, $1.5 \mathrm{oz})$. & \\
\hline Thermometer & Turmeric (store brand, $1 \mathrm{oz})$. & \\
\hline \multirow[t]{2}{*}{ Set of measuring cups/spoons } & Coffee filter (store brand, cone or basket) & \\
\hline & 8 oz. ball glass canning jars or similar ( 1 dozen $)$ & \\
\hline
\end{tabular}

providing clear expectations and appropriate exemplars on report writing resulted in well-written laboratory reports that were similar in quality to those in previous years.

In the first experiment, students calibrated their $25-\mathrm{mL}$ volumetric pipet and performed significance tests (Table 1) to compare their pipet's accuracy to that of another classmate. In the second experiment, students chose an antacid, either Alka-Seltzer (sodium bicarbonate) or Tums (calcium carbonate), and reacted one antacid tablet with excess vinegar (AlkaSeltzer) or $1.0 \mathrm{M}$ citric acid (Tums) to determine the carbonate content. The carbonate content is determined by comparing the difference in weight between the initial reactants and final solution after evolution of carbon dioxide. Since the mass of the carbonate salt is listed in the active ingredients of these over-the-counter medications, students treated these tablets as primary standards. The accuracy and precision of this remote lab was quite acceptable. The percent relative error in the determination of $\mathrm{CaCO}_{3}$ in Tums ranged from 0.3 to $12 \%$ (median $7.5 \%$ ), and the relative standard deviation ranged from 1 to $6 \%$ (median 2.5\%). In the third experiment, students modified the prior procedure to determine the carbonate content in a consumer product (e.g., baking soda toothpaste, calcium carbonate-based toothpaste or cleanser, cat litter, calcium supplement). They had to find the safety data sheet (SDS) for their product to estimate the carbonate content. They also had to calculate the sample size and volume of $1.0 \mathrm{M}$ citric acid to ensure that at least $1.00 \mathrm{~g}$ of carbon dioxide was lost per trial.

The last three experiments involved the assay of a secondary standard (washing soda), which was then used as a titrant in two acid-base titrations. For example, the sodium carbonate purity in the SDS for Arm and Hammer Super Washing Soda [1] is $88 \%(\mathrm{w} / \mathrm{w})$ because of waters of hydration. Students determined the purity of their washing soda by volatilization gravimetry. In the next experiment, students determined the $\mathrm{pK}_{\mathrm{a} 1}$ of ascorbic acid and its mass in a vitamin $\mathrm{C}$ tablet. The washing soda was used to prepare $0.20 \mathrm{M}$ sodium carbonate titrant. Approximately $0.5 \mathrm{~mL}$ increments of titrant were added from a 35-mL plastic syringe, and an inexpensive $\mathrm{pH}$ meter was used to measure solution $\mathrm{pH}$ throughout the titration. Students then determined the titrant density using their $25-\mathrm{mL}$ volumetric pipet, so the mass of each titrant addition could be converted to an accurate volume. Despite the use of a weak base as the titrant, the titration curve generated in this experiment (see ESM) can be used to determine the $\mathrm{pK}_{\mathrm{a} 1}$ of ascorbic acid, which is 4.17. Student $\mathrm{pK}_{\mathrm{a} 1}$ values ranged from 4.14 to 4.52 , although the relative error for the mass of vitamin $\mathrm{C}$ ranged from 14 to $43 \%$. Students also generated a firstderivative plot of their titration curve to more precisely determine the equivalence point volume. The final experiment, which was adapted from a hands-on remote lab posted on the Analytical Sciences Digital Library (ASDL) website [2] involved the determination of potassium bitartrate solubility. Students prepared a saturated solution of Cream of Tartar 2 days ahead of the titration experiment. After decanting or filtering the saturated solution, $25 \mathrm{~mL}$ aliquots were titrated with $0.10 \mathrm{M} \mathrm{Na}_{2} \mathrm{CO}_{3}$. A curcumin indicator, which changes color from yellow to red-orange at $\mathrm{pH} 8$, was used to observe the endpoint. Curcumin was prepared by extraction from powdered turmeric using 70\% isopropyl alcohol.

\section{Remote experiments for an instrumental analysis laboratory}

In light of the COVID-19 pandemic this fall, two hands-on, remote-flexible laboratory experiments were implemented in Instrumental Analysis at Creighton University. One involved the analysis of glucose using amperometry, and the other an analysis of riboflavin using fluorescence spectroscopy. Both experiments are inexpensive, compact, and therefore portable. Both use standard household samples, making the chemistry 
amenable for at-home analysis. The two experiments were first utilized in a standard round-robin laboratory format with relatively little inquiry. They also served as the foundation for less structured, multi-week, inquiry-based group projects focused on method development. The laboratory classes were taught mainly in person. However, these two experiments' portability and remote flexibility were essential when students were isolated due to quarantine and isolation restrictions. In all, 7 out of 27 students needed to complete at least one experiment remotely. Experiences with these two experiments when implemented in hands-on, remote laboratory learning are described here. Learning outcomes of the experiments are given in the ESM.

An at-home experiment for determining glucose in beverages using a commercial glucometer was developed. This experiment was adapted from a report that used blood-glucose test strips for introducing enzyme electrodes and modern biosensors to undergraduate students [3]. An overview and background information on amperometric blood-glucose meters and test strips are provided on the ASDL website [4]. Table 3 provides a list of materials needed for the experiment. A student handout, approximate costs of materials, instructor guidelines, and evaluation guidelines are provided in the ESM.

The experiment background in the student handout covers the fundamental chemistry behind self-monitoring blood-glucose systems (SMBGs). This includes the reactions occurring at the enzyme electrode, information about diabetes, and the accuracy requirements for SMBGs. To perform the experiment, students (1) prepare glucose standards from a stock standard solution; (2) properly dilute their unknown and sugary beverage; (3) prepare a calibration curve and determine the glucose concentrations in the beverage and unknown samples; and (4) perform a replicate analysis to determine the precision of the method. From these data, students are asked to calculate and report (a) the original glucose concentration of the unknown; (b) the concentration of glucose in the beverage sample in $\mathrm{g} / \mathrm{L}$; (c) the precision in \%RSD; and (d) the limit of detection in $\mathrm{mM}$. A reporting sheet is provided with the student handout.

Given the solutions and supplies outlined in Table 3, students can perform this experiment entirely at home. Performing the dilutions with a micropipette would be the most accurate; however, a less costly method would be to deliver liquids by mass using a pocket balance. Students who were on campus but conducting the experiment remotely could take a micropipette home. The cost of the glucose meter, test strips, and other consumables is quite low, as shown in Table S2. The procedures are safe, as the solutions contain only glucose and are at a neutral $\mathrm{pH}$.

An at-home experiment was developed for the fluorometric determination of riboflavin (vitamin $\mathrm{B}_{2}$ ) in energy drinks. An overview and background information on the fundamental principles of fluorescence and vitamin $\mathrm{B}_{2}$ are provided on the ASDL website [5]. Table 4 provides a list of materials needed for the experiment. A student handout, approximate costs of materials, instructor guidelines, and evaluation guidelines are provided in the ESM.

To perform the experiment, students (1) prepare riboflavin standards from a stock standard solution, (2) obtain a calibration curve, and (3) determine the riboflavin concentrations of the beverage and unknown samples. From these data, students are asked to calculate and report (a) the original riboflavin concentration of the unknown; (b) the concentration of

Table 3 Contents of take-home kits for amperometric glucose determination

\begin{tabular}{|c|c|c|}
\hline Items & Amount & Notes \\
\hline \multicolumn{3}{|l|}{ Solutions and samples } \\
\hline $24 \mathrm{mM}$ glucose standard solution* & $5 \mathrm{~mL}$ & Provide students with the actual concentration (e.g., $24.26 \mathrm{mM}$ ) \\
\hline Buffer & $10 \mathrm{~mL}$ & e.g., $0.1 \mathrm{M} \mathrm{PBS}$ pH $7.5+0.1 \mathrm{M} \mathrm{NaCl}$ \\
\hline Beverage sample* & $1 \mathrm{~mL}$ & Gatorade or choice of sugary beverage \\
\hline Unknown sample* & $1 \mathrm{~mL}$ & Dilute the stock standard to an appropriate level (e.g., to between 5 and $15 \mathrm{mM}$ ) \\
\hline \multicolumn{3}{|l|}{ Analytical equipment } \\
\hline Self-monitoring blood-glucose system (SMBG) & 1 & e.g., True Metrix SMBG \\
\hline Test strips & At least 20 & Store in original container \\
\hline $1000-\mu \mathrm{L}$ variable volume micropipette & 1 & Alternatives for volume measurement: syringe or pocket balance \\
\hline \multicolumn{3}{|l|}{ Consumables } \\
\hline Micropipette tips & at least 20 & \\
\hline Plastic centrifuge tubes $(1.5 \mathrm{~mL})^{* *}$ & 10 & For solution preparation \\
\hline Small weighboats & 5 & \\
\hline
\end{tabular}

*Instructors should keep glucose solutions refrigerated until handing out to students. If students take kits home well in advance of performing the experiment, they should also keep these refrigerated

**A small test tube rack to hold the $1.5-\mathrm{mL}$ centrifuge tubes is helpful, if available 
Table 4 Contents of take-home kits for the fluorometric riboflavin determination

\begin{tabular}{|c|c|c|}
\hline Items & Amount & Notes \\
\hline \multicolumn{3}{|l|}{ Solutions and samples } \\
\hline $50-60 \mu \mathrm{M}$ riboflavin standard solution* & $5 \mathrm{~mL}$ & Provide students with the actual concentration (e.g., $54.78 \mu \mathrm{M}$ ) \\
\hline Buffer & $15 \mathrm{~mL}$ & e.g. $0.2 \mathrm{M}$ citrate $\mathrm{pH} 3.5$ \\
\hline Beverage sample* & 4-5 mL & Lo-Carb Monster Energy ${ }^{\text {TM }}$ \\
\hline Unknown sample* & $4-5 \mathrm{~mL}$ & Dilute the stock standard to an appropriate level (e.g., to 4 to $10 \mu \mathrm{M}$ ) with buffer \\
\hline \multicolumn{3}{|l|}{ Analytical equipment } \\
\hline Portable fluorimeter & 1 & $\begin{array}{l}\text { e.g., Vernier Go Direct SpectroVis Plus } \\
\text { *Must be capable of excitation between } 400 \text { and } 500 \mathrm{~nm} \text { and emission collection } \\
\text { between } 500 \text { and } 550 \mathrm{~nm}\end{array}$ \\
\hline Pocket balance & 1 & Should have at least 2 significant figures after decimal, preferably 3 \\
\hline \multicolumn{3}{|l|}{ Consumables } \\
\hline Disposable $3.5-\mathrm{mL}$ polystyrene cuvettes $\mathrm{w} /$ lids & $7-10$ & Lids are needed so that students can make solutions directly in the cuvettes \\
\hline Disposable transfer pipettes & $7-10$ & \\
\hline Black plastic centrifuge tubes & & \\
\hline
\end{tabular}

*For best results, instructors should keep riboflavin-containing solutions refrigerated and stored in amber or black containers. If students take kits home well in advance of performing the experiment, they should also keep these refrigerated

riboflavin in the beverage sample in $\mathrm{mg} /$ serving; and plot their external calibration to journal article figure standards. A reporting sheet is provided with the student handout.

All the required materials are safe to be used at home and for transport. Most of the materials needed to complete the experiment are inexpensive or common laboratory consumablesexcept for the spectrophotometers, which can be prohibitively expensive (currently, \$399). Alternative fluorometric and spectrophotometric setups at a fraction of the cost have been experimented with, building on others' work using LED excitation sources, 3D-printed structures, and smartphone cameras, or photoresistors, for detectors [6-9]; however, these methods were not deployed in remote laboratory learning for Fall 2020.

Evaluation of student performance on the two experiments based on accuracy indicated no statistical difference, whether conducted at home or in the lab. Sample student calibration curves and data reported are shown for both experiments in the ESM. Student feedback confirmed that they felt less rushed when performing experiments at home than in the standard 3-h lab format. One drawback was that students did not synchronously perform the experiment during the lab time and could not ask questions in real time. A future planned improvement is to deliver the lab experience synchronously so that students can answer questions in real time. There is also a plan to provide laboratory kit unboxing and demonstration videos for the lab experiment.

In general, survey results indicated that students found both experiments straight-forward. Though, in the portable fluorescence experiment, several struggled with the concept of preparing standard solutions gravimetrically. This issue was compounded in implementation because students were not explicitly told what concentrations to prepare from the riboflavin stock standard. This was done intentionally to have students practice making external calibration curves independently before they begin group projects. Alternatively, one could assign more prescriptive dilution instructions.

Some students wrote that having peers who had completed the experiment helped when working remotely. In addition to the ideas described previously, instructors could have a discussion board to address common queries that students may have when conducting the experiment remotely and encourage students in the class to answer questions from others. The instructor can monitor what information is shared, and responses remain public and searchable to students working on those experiments later in the term.

Lastly, these experiments served as the foundation for projects using the same equipment. Remote-flexible group projects completed by students based on these experiments are included in the ESM.

Through the two remote-flexible experiments, students obtained hands-on experiences with quantitative electrochemical and spectroscopic methods. Students were able to plan dilution schemes, prepare solutions, and apply external calibration methods to determine glucose and riboflavin concentrations in unknown solutions and consumer beverages. Students also gained experience preparing and reporting their results with a publication-style figure and figure caption.

\section{Student research projects within an online analytical chemistry laboratory}

Course-based undergraduate research experiences (CUREs) have become an increasingly popular method to provide a 
larger number of students with the benefits of participating in research [10]. At Southwestern University, CUREs are integrated into the curriculum through a series of upper-level laboratory courses in different chemistry sub-disciplines. For example, students in the Advanced Laboratory in Analytical Chemistry course typically complete a semester-long research project that introduces them to analytical methodology and instrumentation, basic statistical analysis, and techniques of sample preparation, extraction, and calibration. In response to the COVID-19 pandemic, Southwestern University moved all laboratory courses primarily to remote instruction this fall. When transitioning the analytical lab course fully online, it was important to provide students with hands-on experiences while also maintaining the learning outcomes associated with an in-person CURE to the greatest extent possible. In particular, the goal was to develop a student-driven "authentic inquiry" project [11] in which students worked cooperatively in small groups to propose a novel research question; identify and conduct analytical experiments to answer that question; determine appropriate statistical analyses for their experimentally collected data; contextualize their results within the broader scientific literature; and present their findings in oral and written formats.

Scaffolding activities throughout the semester (Fig. 1) to prepare students for the research project proved particularly important for an online lab course [12]. The semester began with students participating in workshops on topics such as analytical figures of merit and calibration, spectroscopy, and statistical analysis. Because the upper-level laboratory courses are designed to stand alone and are not tied to a lecture class, these workshops provided an introduction to foundational analytical chemistry concepts. Students were placed in groups within online breakout rooms and worked collaboratively on active learning materials adapted from the Analytical Sciences Digital Library [13] as well as POGIL (process-oriented guided inquiry learning) style worksheets [14].

Following the workshops, students then constructed their own spectrometers utilizing smartphones as detectors [9]. Building the spectrometers was a guided inquiry activity [11] with students required to have some common elements in their instrumental design, such as a 1-cm polystyrene cuvette as the sample holder and a smartphone paired with the ImageJ software [15] for data collection and processing (the student handout for this activity is provided in the ESM). However, students were encouraged to experiment with optimizing other components, such as their light source and housing, which led to considerable variation in spectrometer design among students in the course. These spectrometers provided students with inexpensive and durable instruments to measure absorbance values at home and were central to the research projects that were carried out later in the semester. In preparation for their research projects, students also characterized their individual smartphone spectrometers by analyzing figures of merit such as the linear dynamic range, sensitivity, and detection limit of a food dye. Additionally, they conducted two open inquiry experiments [11] to determine the concentrations of food dyes (both individually and as a mixture) found in candy straws and a bottled sports beverage. These lab activities, which were completed synchronously by students working in assigned groups within online breakout rooms, gave students practice collaboratively designing experiments while also providing them with opportunities to optimize their smartphone spectrometers and address differences that arose in their results due to variations in spectrometer design. To support these experiments, students were provided with a take-home laboratory kit [16] which included consumables (such as gloves and plastic cuvettes), beakers, a volumetric flask, a 10-mg balance, a $100-\mu \mathrm{L}$ mini-pipette and $10-\mathrm{mL}$ graduated volumetric pipette, food dye standards, and candy and beverage samples (further details about the equipment boxes are provided in the ESM).

Student groups were also required to develop a written project proposal to help them plan and prepare for their research study. Prior to submitting the proposal, each student group met with the instructor to brainstorm project ideas. These meetings were critical since the online lab format led to numerous experimental constraints-such as the need to select reagents that were safe for use at home- which had to be taken into account along with instrumental limitations of the smartphone spectrometers (e.g., they can only detect analytes that absorb in the visible region of the spectrum). Final proposals included an overview of the system of study, a research hypothesis, the gap in the literature that the study addresses, a detailed summary of the research plan, and a list of supplies, if needed. Following submission of the proposals, the instructor met with groups again to discuss their proposed experiments and finalize details for distributing samples, analytical standards, and reagents to group members. This entire process was scheduled early in the semester to allow sufficient time to order project supplies and make them available for students to pick up at a designated campus location or to send via mail to students who were fully remote. Students had 3 weeks to complete their experiments, and each group submitted a final journal-style manuscript based on their results. Additionally, oral online presentations occurred during the last lab session of the semester, providing groups with an opportunity to explain their research results to others in the class as well as answer questions about their projects (handouts for each of these course assignments are provided in the ESM).

Despite the challenges associated with designing a research study for a non-laboratory setting, students collaborated effectively within the online course environment to develop projects that were both creative and interesting. All of the studies involved the analysis of common supermarket samples such as wine, kombucha, and berries. Comparing levels of 


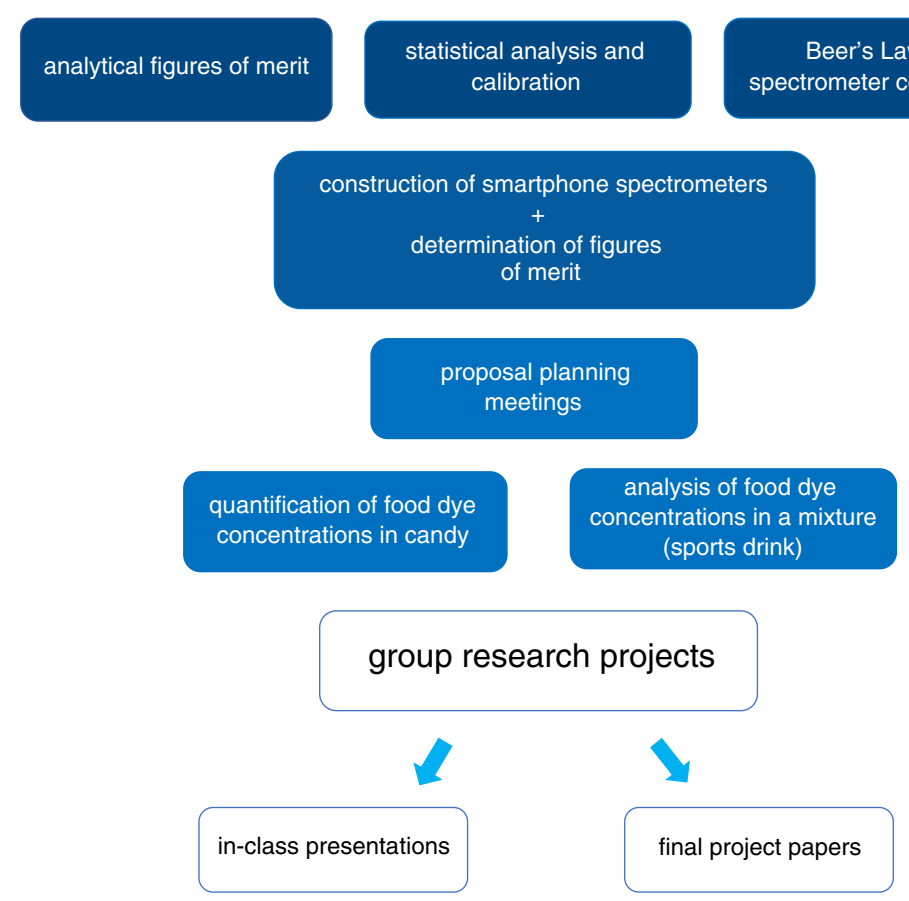

\section{foundation-building \\ workshops \\ (3 weeks)}

constructing

instrumentation

(2 weeks)

project planning

(1 week)

guided-inquiry

experiments

(2 weeks)

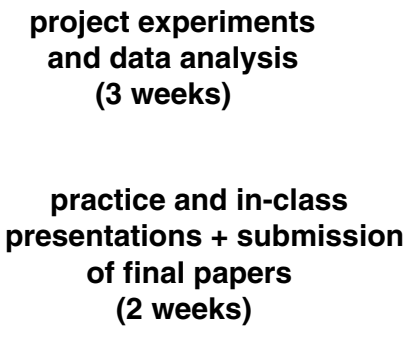

Fig. 1 Semester plan for an online lab course incorporating student-designed research projects

anthocyanins, blue-red plant pigments, among samples, were the most common project focus and gave students the opportunity to study a relevant analyte known to impart a variety of health benefits in humans [17]. Although these research studies were much smaller in scope than the ones that students complete in the lab course during a typical semester, the online projects accomplished the same overall learning goals while solidifying student understanding of analytical concepts such as extraction, calibration, and statistical analysis. Additionally, the scaffolding activities that were developed for the online lab this semester better prepared students to design their own research projects, and many of these activities will be integrated into the course following the pandemic.

\section{Concluding comments}

This article describes three examples of laboratory experiences that students in analytical chemistry courses can complete while studying remotely. These experiences provide students with hands-on laboratory work and incorporate learning outcomes that many instructors have for the laboratory component of analytical chemistry courses. All of the experiments described herein are safe to complete in remote settings without the usual safety items expected in a university laboratory. Additionally, these experiments can be accomplished at a minimal cost and did not require additional personnel since they were taught by individual instructors (similar to a traditional in-person laboratory). Instructors and students were satisfied with these experiences and will keep using them as long as our courses continue to involve remote instruction.

Supplementary Information The online version contains supplementary material available at https://doi.org/10.1007/s00216-020-03142-1.

Acknowledgments The authors wish to acknowledge their departments at Creighton University, Southern Oregon University, and Southwestern University for supporting this work.

Funding Support for this work was provided by the United States National Science Foundation through grant numbers 1624898 and 1624956. JFD and EMG received support from the National Institute for General Medical Science (NIGMS) (5P20GM103427), a component of the United States National Institutes of Health (NIH).

\section{Compliance with ethical standards}

Conflict of interest The authors declare that they have no competing interests.

\section{References}

1. Ingredient disclosure. https://churchdwight.com/ingredientdisclosure/laundry-fabric-care/40002697-arm-hammer-superwashing-soda.aspx. Accessed 13 Nov 2020.

2. Harrison C. Gravimetric acid-base titration - labs and simulations. https://remotelabs.asdlib.org/gravimetric-acid-base-titration/. Accessed 13 Nov 2020.

3. Wang J, Maccà C. J Chem Educ. 1996;73:797-9. 
4. Determination of glucose in beverages using a blood-glucose meter https://remotelabs.asdlib.org/determination-of-glucose-inbeverages-using-a-blood-glucose-meter/. Accessed 3 Dec 2020.

5. Fluorometric determination of riboflavin in energy drinks https:// remotelabs.asdlib.org/fluorometric-determination-of-riboflavin-inenergy-drinks/. Accessed 3 Dec 2020.

6. Porter LA, Chapman CA, Alaniz J. J Chem Educ. 2017;94:105-11.

7. Print, build, and use your own LED photometer https://remotelabs. asdlib.org/print-build-and-use-your-own-led-photometer/. Accessed 3 Dec 2020.

8. Kovarik ML, Clapis JR, Romano-Pringle KA. J Chem Educ. 2020;97:2185-95.

9. Destino JF, Cunningham K. J Chem Educ. 2020;97:2960-6.

10. Bangera G, Brownell SE. CBE: Life Sci Educ. 2014;13:602-6.

11. Buck LB, Bretz SL, Towns MH. J Coll Sci Teach. 2008;38:52-8.

12. Doo M, Bonk C, Heo H. Int Rev Res Open Dis Learn. 2020;21:6080.

13. Shorter activities. http://community.asdlib.org/activelearning materials/activities/. Accessed 30 Nov 2020

14. Lantz J, Cole R. Analytical chemistry: a guided inquiry approach instrumental analysis collection. New Jersey: Wiley; 2015.

15. Schneider CA, Rasband WS, Eliceiri KW. NIH image to ImageJ: 25 years of image analysis. Nat Methods. 2012;9:671-5.

16. Miles DT, Wells WG. J Chem Educ. 2020;97:2971-5.

17. He J, Giusti MM. Annu Rev Food Sci Technol. 2010;1:163-87.

Publisher's note Springer Nature remains neutral with regard to jurisdictional claims in published maps and institutional affiliations.

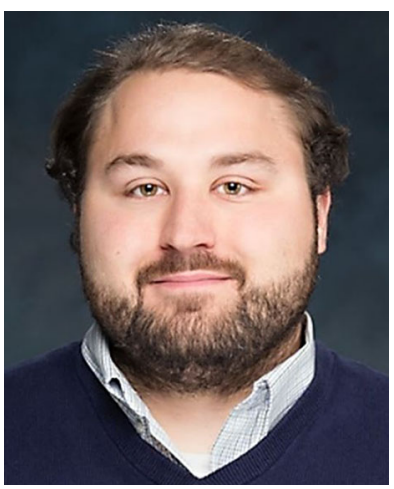

Joel F. Destino is Assistant Professor of Chemistry at Creighton University in Omaha, NE, USA, who has taught primarily analytical chemistry courses. $\mathrm{He}$ is passionate about undergraduate research and incorporating active and project-based learning in his classes, along with memes/ social media, and social justice and equity issues. Recently, his teaching efforts have focused on developing at-home-friendly, remote laboratory experiments. More information about his work can be found at https://www.creighton.edu/faculty-directory-profile/ 1495/joel-destino, and his students' memes can be viewed at (a) QuantMemes on Instagram and Twitter.

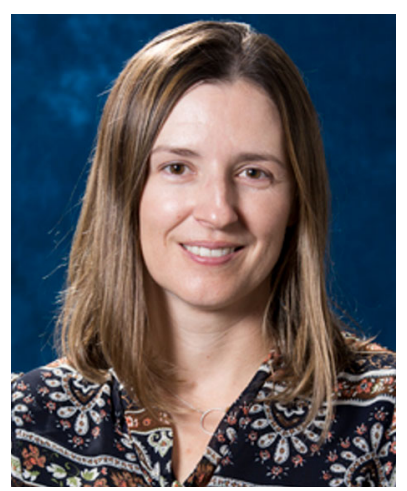

Erin M. Gross is Professor of Chemistry at Creighton University in Omaha, NE, USA. She is passionate about active learning and teaches a wide range of courses in analytical, green chemistry, and introductory chemistry. She is an active researcher with undergraduate students and participates in the Institutional Development Award Program (IDeA) Networks of Biomedical Research Excellence (INBRE) program in Nebraska. Further details of her accomplishments can be found at https://www.creighton.edu/faculty-directoryprofile/211/erin-gross.

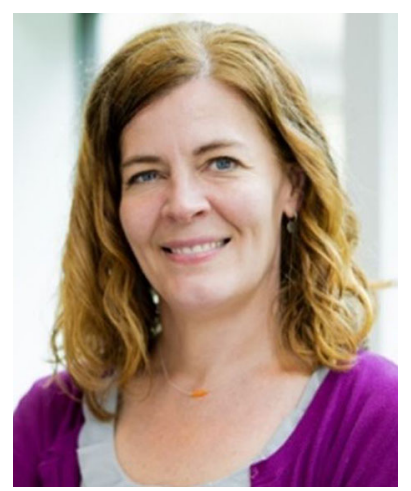

Emily D. Niemeyer is Professor of Chemistry and the Herbert and Kate Dishman Chair in Science at Southwestern University in Georgetown, TX, USA. As the Program Director for Southwestern's Inquiry Initiative, she successfully oversaw a transition to an inquirybased curriculum across the institution's science departments while significantly expanding undergraduate research opportunities for underrepresented students. She teaches a wide range of courses in analytical, environmental, and introductory chemistry as well as classes for non-science majors. She is an active researcher with undergraduate students, and further details of her accomplishments can be found at https://www.southwestern.edu/live/profiles/25709-emilyniemeyer.

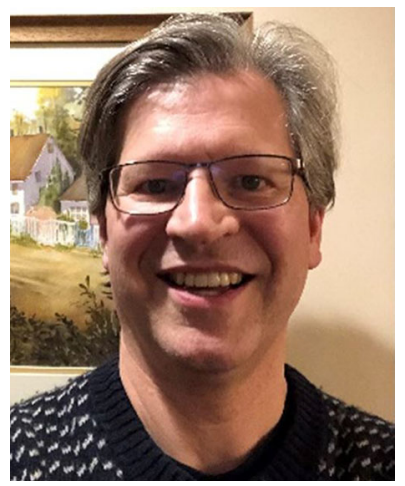

Steven C. Petrovic is Professor of Chemistry at Southern Oregon University in Ashland, OR, USA. He teaches courses in analytical chemistry and general chemistry, as well as courses in wine production and the chemical analysis of wine. His current research focus is on the electrochemistry of wine phenolics and on the development of experiments for the undergraduate analytical chemistry laboratory. He has been associated with the Analytical Sciences Digital Library (ASDL) since 2005, and he is active in the development of learning modules and active learning experiences, which can be found online at www.asdlib.org. 